\title{
A NECESSIDADE DE REGULAÇÃO DO TRABALHO SOB DEMANDA POR MEIO DE APLICATIVO: ANÁLISE CRÍTICA DO PROJETO DE LEI N. 3.748/2020
}

\author{
Ana Paula Heimovski ${ }^{1}$ \\ Sandra Paula de Souza Mendes ${ }^{2}$
}

RESUMO: Objetiva-se demonstrar a necessidade de regulamentação do trabalho sob demanda por meio de plataformas digitais, analisando o Projeto de Lei $\mathrm{n}^{\circ}$ 3.758/20. Questiona-se se o projeto de lei está apto a acabar com a controvérsia existente sobre a relação de emprego na prestação de serviços por meio de aplicativos. A metodologia de pesquisa adotada foi bibliográfica. Como resultado da pesquisa, é imprescindível que seja criada uma lei para regulamentar a prestação de serviços por meio de aplicativo, evitando a insegurança jurídica que paira sobre a questão, e assim, fomentar esta prestação de serviços no mercado brasileiro.

PALAVRAS-CHAVE: Trabalho sob demanda; Flexibilização; PL 3748/2020; Plataforma Digital; Proteção do trabalhador.

\section{THE NEED TO REGULATE WORK ON DEMAND THROUGH AN MOBILE APP: CRITICAL ANALYSIS OF THE BILL 3.748/2020}

\begin{abstract}
The objective is to demonstrate the need to regulate work on demand through digital platforms, analyzing Bill No. 3,758 / 20. It is questioned whether the bill is capable of ending the existing controversy over the employment relationship in the provision of services through mobile app. The research methodology adopted was bibliographic. As a result of the research, it is essential that a law be created to regulate the provision of services through an application, avoiding the legal uncertainty that hangs over the issue, and thus, foster this provision of services in the Brazilian market.
\end{abstract}

KEYWORDS: Work on demand; Flexibilization; PL 3748/2020; Digital platform; Worker protection.

\section{1- Introdução}

Há muito a classificação tradicional de trabalhadores e autônomos não engloba toda a classe de prestadores de serviços no país e assim coloca em risco de vulnerabilidade sócio econômica milhares de pessoas que ficam sem qualquer tipo de segurança jurídica.

Diante do avanço tecnológico, surgiram novas relações de trabalho, como a dos prestadores de serviços por meio das plataformas digitais, que não se enquadram na clássica classificação de empregado proposta pela Consolidação das Leis do Trabalho (CLT). A nova

\footnotetext{
${ }^{1}$ Advogada. Mestranda no Programa de Mestrado em Direito da Universidade FUMEC.

${ }^{2}$ Advogada. Mestranda no Programa de Mestrado em Direito da Universidade FUMEC
} 
onda de serviços sendo prestados fora das dependências de uma empresa, pelos meios virtuais se tornou cada dia mais comum em nossa realidade, e sem uma roupagem da tradicional figura do empregado. Todavia, o trabalhado digno, ainda que considerado autônomo, não pode ser desprotegido pelo Direito do Trabalho.

Observa-se desigualdade econômica entre os trabalhadores e as empresas proprietárias de plataformas, de forma que deverá haver equilíbrio nesta relação para proteção do prestador de serviço.

No entanto, há ampla discussão judicial acerca da classificação e do enquadramento dos prestadores de serviços sob demanda por aplicativos como empregados, uma vez que não há o cumprimento de todos os requisitos legais impostos pela legislação em vigor para tanto. Por outro lado, classificando como autônomos, obviamente não terão os direitos garantidos aos empregados e os colocarão em situação de evidente vulnerabilidade.

Buscando uma alternativa para regular o trabalho prestado no capitalismo de plataforma, surgiu o projeto de Lei 3.748/2020, na qual o presente tem como escopo fazer uma análise crítica do referido projeto de Lei.

O marco teórico que se adota é o projeto de Lei 3.748/2020, tendo como metodologia o meio de pesquisa bibliográfica por método dedutivo.

\section{2- O Trabalho sob demanda por meio de aplicativos}

Acompanhando o avanço tecnológico, o trabalho sob demanda tem crescido não só no Brasil, mas em todo o mundo, e para analisar se o PL 3.748/2020 preenche a lacuna legislativa de forma adequada, é imperioso analisar as características deste tipo de trabalho.

O trabalho sob demanda por meio de aplicativos, ocorre quando há a oferta e a demanda da força de trabalho de forma on-line, sendo as atividades de execução do serviço realizadas presencialmente.

Segundo Kalil, é a relação de trabalho triangular, em que a plataforma viabiliza a combinação entre oferta e demanda de mão de obra por meio do software para a execução de uma atividade nas proximidades ou no próprio local em que está situado fisicamente o tomador de serviços. (Kalil, 2020).

O trabalho ocorre da seguinte maneira: (i) o usuário da plataforma acessa o aplicativo em busca de um serviço e o solicita; (ii) em algumas plataformas, é possível indicar determinadas características que o trabalhador deve ter para executar a atividade - como 
tempo de experiência -, ao passo que em outras, essa opção não é apresentada; (iii) a oferta solicitada é apresentada aos trabalhadores que estão disponíveis e atendem aos critérios da plataforma (como os casos em que se dá preferência aos fisicamente mais próximos do usuário) e/ ou do cliente; (iv) em algumas plataformas, o usuário também pode escolher o trabalhador que executará a atividade; (v) havendo a combinação entre oferta e demanda de mão de obra, que pode ocorrer pela ordem de chegada do trabalhador disponível, pela escolha do trabalhador feita pelo usuário ou pela distribuição da atividade feita pela plataforma, a tarefa é executada; (vi) terminada a atividade, o cliente realiza o pagamento para a empresa, que normalmente retém a sua parte e, em seguida, repassa os valores devidos ao trabalhador; (vii) geralmente os trabalhadores são avaliados pelos usuários e, em algumas plataformas, os prestadores de serviços também avaliam os clientes. (Kalil, 2020).

Portanto, na relação triangular, o trabalhador é o responsável pela execução direta do serviço, como por exemplo os entregadores e os motoristas.

\section{1- O conceito do trabalho por meio de plataformas digitais e suas características}

A avanço tecnológico criou novas frentes de trabalho e o uso da plataforma digital pelos consumidores, alterou direção comercial da oferta de produtos para a prestação de serviços.

As plataformas digitais se constituem por um ambiente que relaciona consumidores a qualquer tipo de produto ou serviços, e não só as grandes, mas as pequenas empresas e até mesmo qualquer pessoa podem se tornar fornecedores de produtos e serviços por meio da internet.

A popularização do acesso à internet através de aparelhos celulares, viabilizou ainda mais o acesso às plataformas digitais.

Além do mais, o principal fator de sucesso das plataformas digitais é a lógica da intermediação, na qual os problemas de coordenação nas transações de mercado são resolvidos por meio do encurtamento das distâncias e da facilitação do contato entre oferta e demanda. $\mathrm{O}$ sucesso na promoção da intermediação fez com que as plataformas atingissem distintos domínios de circulação, como os mercados de trocas on-line (p. ex., Amazon e Spotify), as mídias sociais (p. ex., Facebook e Twitter), a economia de compartilhamento (p. ex., Uber e Airbnb), a crowdsourcing (p. ex Upwork e Amazon Mechanical Turk) e crowdfunding (p. ex., Kickstarter) (LANGLEY, Paul; LEYSHON, Andrew, 2016) 
Há diversidade de conceitos para abordar as novas formas de trabalho introduzidas por meio de prestação de serviços sob demanda de plataformas digitais, na qual destaca-se entre as mais populares: economia de compartilhamento, economia de bico (gig economy), uberização e capitalismo de plataforma.

A expressão "economia de bico" que também é muito utilizada para descrever o desenvolvimento de atividades econômicas em plataformas digitais (gig economy) transmite a ideia que as atividades disponíveis são de curto prazo e intermitentes, e é utilizada em diversos setores.

O trabalho informal tem como características principais a instabilidade, temporariedade (transitório), insegurança e a rotatividade. Por sua vez, a economia de bico é uma espécie de trabalho informal realizado em plataformas digitais.

Já o termo uberização, também muito utilizado, decorre do modelo de negócios da empresa de transportes Uber, na qual se trata de uma mera intermediadora eletrônica entre oferta (motoristas) e demanda (clientes) por meio de um aplicativo digital.

Entre as principais características do modelo Uber de trabalho cita-se a à restrição aos direitos trabalhistas, posto que se recebe exatamente o que se produziu ou foi contratado, sem quaisquer direitos como os celetistas e ainda que o trabalhador arca com os custos e riscos.

Desse modo, o modelo Uber de negócio disseminou amplamente e é adotado por diversas empresas. Isto porque a Uber considera os motoristas como "parceiros" e os classifica como trabalhadores autônomos. ${ }^{3}$

Através da Uber pode-se ilustrar o crescimento do trabalho sob demanda no Brasil, com mais de 14 milhões de viagens por dia e em outubro de 2016, esta plataforma digital possuía 50 mil trabalhadores, com 4 milhões de usuários. Em abril de 2018, já possuía 500 mil motoristas e 20 milhões de usuários, um aumento em 10 e 2,5 vezes, respectivamente, em apenas um ano e meio. Em fevereiro de 2020, contava com 1 milhão de motoristas e 22 milhões de usuários. (FATOS E DADOS SOBRE A UBER, 2021).

Por fim, ao conceituar o serviço como capitalismo de plataforma diverge da ideia de compartilhamento do primeiro conceito, vez que promove atividades diversas e redistributivas, e mais, possibilita outras formas de trocas em rede.

\footnotetext{
${ }^{3}$ UBER. Fatos e dados sobre a Uber. cit.; Id. Termos e condições gerais dos serviços de intermediação digital. São Paulo: mimeo, 2018, p. 9-10. Segundo os termos e condições gerais dos serviços de intermediação digital, "a relação entre nós é exclusivamente de partes contratantes independentes. Estes Termos não constituem um contrato de trabalho, nem criam uma relação de trabalho, joint venture, parceria, ou de agenciamento entre nós, bem como não lhe concede autoridade de nos vincular ou de se apresentar como nosso(a) empregado(a), agente ou representante autorizado" (Id. Ibid., p. 9-10).
} 
O capitalismo de plataforma é a concretização de diversos movimentos para produção enxuta que tiveram início na década de 1970 que desencadeou por exemplo, a terceirização.

O capitalismo do século XXI tem como uma das principais matérias primas os dados, cujo compartilhamento de dados é um importante instrumento econômico. Os dados dos consumidores ficam armazenados nas diversas plataformas digitais de compra, e estas informações têm um valor econômico.

As formas de trabalho no capitalismo de plataforma se dará sob demanda por meio de aplicativos e crowdwork, sendo que este último, não é objeto do presente e se refere aos trabalhos que são executados independentemente da localização geográfica dos prestadores de serviços, das plataformas e clientes, como por exemplo a Amazon Mechanical Turk. Por sua vez, o trabalho sob demanda vem abarcar os trabalhos que são oferecidos online, porém, com local de execução determinado, como por exemplo, o trabalho dos motoristas da Uber.

Não há dúvida que o trabalho desenvolvido por meio de aplicativos pode promover um reduzido custo e fomentar o crescimento econômico inserindo mais pessoas ao mercado de trabalho.

Todavia, não se pode deixar de considerar que o referido trabalho aumenta a desigualdade social na medida em que introduz a precariedade do trabalho, na qual o prestador de serviço não tem poder de negociação, estabilidade, previdência social, possui remuneração inferior ao do trabalhador formal.

Desse modo, enquanto as empresas que exploram o serviço, expandem pelo baixo custo, pela falta de regulação na outra ponta encontram-se milhares de trabalhadores desprotegidos.

Por meio do capitalismo de plataforma é possível identificar que há novas formas de relações de trabalho e o novo modelo precisa ser regulado, já que os trabalhadores podem ser demandados a qualquer dia e horário, em qualquer lugar, com a consequente alteração do cotidiano.

A busca desenfreada pelos pontos que qualificam os prestadores de serviços que ficam na ponta do trabalho contratado por meio digital coloca os mesmos em contato diário e integral com seus interlocutores, através de atendimentos on line para concretização das tarefas digitais.

Assim, mais importante que a diversidade de conceitos, o crescimento do serviço põe milhares de trabalhadores em situação de precariedade, sendo uma questão social de grande relevância no momento. 


\section{2- A necessidade de se regular o serviço prestado sob demanda por meio de aplicativos}

Segundo consta na justificativa do projeto de lei 3.748/2020, dados do IBGE (CRELIER, 2019) mostram um intenso crescimento dessa modalidade de trabalho, que já abrange milhões de brasileiros. Segundo o site Infomoney (APPS COMO UBER E IFOOD SÃO FONTE DE RENDA DE QUASE 4 MILHÕES DE AUTÔNOMOS, 2019), “aplicativos de serviços - como Uber, 99, iFood e Rappi - se tornaram, em conjunto, o maior 'empregador' do País, com quase 4 milhões de trabalhadores autônomos utilizando hoje as plataformas como fonte de renda"

Após a pandemia da Covid - 19, o serviço prestado por meio de plataformas digitais, que já vinha crescendo, aumentou de forma significativa. Isto porque em decorrência do isolamento social, os consumidores passaram a adquirir produtos por plataformas digitais, havendo necessidade de entregador em domicílio.

Cita-se a título de exemplo, que os trabalhadores que sofrem acidentes ou adoecem durante a prestação de serviços não são acobertados pela empresa que os contratou e não há previdência social, bem como a prestadora de serviço gestante, não tem também auxílio maternidade ou qualquer outro tipo de proteção durante após o parto.

Diante disto, a classe dos trabalhadores tem se unido buscando a regulação do serviço e assim suprir as deficiências para efetivação do trabalho digno.

Grande prova foi a mobilização em nível nacional ocorrida pelos entregadores em 01.07.2020 (RIBEIRO, 2020), ou seja, em plena pandemia causada pelo vírus Covid-19, na qual houve uma paralisação geral da categoria contrária à precarização.

É importante apurar se os contratados através das plataformas digitais são classificados como autônomos ou empregados, ou se surge uma terceira modalidade de prestação de serviço.

No Brasil, não se tem uma definição e diante das peculiaridades específicas do conceito de empregado e autônomo, o ideal é que seja definida uma terceira modalidade intermediária como vem ocorrendo nos demais países.

De qualquer forma, o enquadramento dos prestadores de serviços por demanda como empregado ou autônomos ou o surgimento de outra modalidade precisa ser regulado, suprindo a lacuna legislativa, a fim de que elimine a desigualdade social, com a proteção dos trabalhadores e crie segurança jurídica às relações. 


\section{3- Os requisitos legais para o reconhecimento de um vínculo de emprego e análise de aplicação ou não nas relações de trabalho sob demanda por meio de aplicativo.}

Certo é que com o avanço da tecnologia novas formas de prestação de serviços vêm sendo criadas, trazendo a necessidade de que a legislação seja analisada à luz da nova realidade, colocando o Judiciário no desafio de se evitar a precarização da mão de obra, garantindo aos trabalhadores um patamar civilizatório mínimo.

Por ser o trabalho sob demanda uma prestação de serviços, mesmo que essa se dê com a utilização de plataformas digitais, necessário se faz a análise da situação sob a ótica do Direito do Trabalho que regulamenta tanto as relações de trabalho, quanto as relações de emprego, conforme será exposto a seguir.

\subsection{Requisitos legais para configuração do vínculo de emprego}

A relação de emprego diverge da relação de trabalho.

A relação de trabalho corresponde ao vínculo jurídico estipulado, expressa ou tacitamente, entre um trabalhador e uma pessoa física ou jurídica, que o remunera pelos serviços prestados. Contudo, diferente da figura da relação empregatícia, um trabalhador autônomo, assume o risco da atividade profissional que exerce, ao contrário do emrpegado. (SUSSEKIND, 2009).

Portanto, a relação de trabalho é uma mera prestação de serviços em que o trabalhador assume todos os riscos de sua atividade econômica.

Em contrapartida, a relação de emprego, conceituado como empregado, está prevista na Consolidação das Leis do Trabalho, e protegida por essa legislação, tem seus requisitos descritos no artigo $3^{\circ}$ desta, em que se considera o empregado como "toda pessoa física que prestar serviço de natureza não eventual a empregador, sob a dependência deste e mediante salário" (BRASIL, 1943). Já empregador, conforme dispõe o artigo $2^{\circ}$ da CLT, pode ser conceituado como "a empresa, individual ou coletiva, que, assumindo os riscos da atividade econômica, admite, assalaria e dirige a prestação pessoal de serviços" (BRASIL, 1943). 
Infere-se dos dispositivos legais que para a configuração da relação de emprego, que tem proteção no ordenamento jurídico (CLT), é necessária a presença de todos os requisitos abaixo:

a) Pessoalidade - Deve ser a prestação de serviços ser intuito personae com o empregado, que é sempre pessoa física. O empregado deverá prestar serviços pessoalmente e somente em casos excepcionais, com consentimento, tácito ou expresso, do empregador temse admitido a substituição do prestador do trabalho. (LEITE, 2018).

b) Não eventualidade - Emprego é aquele de presta serviços de maneira regular, habitual e constante ao seu empregador. Figura essa diferente das prestações de serviços eventuais, esporádicas que não caracterizam a relação de emprego.

c) Onerosidade - A contraprestação remunerativa pelo trabalho exercido pelo empregado. O trabalho voluntário, por caridade, não detém este requisito, fato pelo qual não é protegido pela legislação trabalhista.

d) Subordinação - Um dos mais controversos requisitos quanto a sua definição, e o mais relevante para a caracterização da relação de emprego, a subordinação é dependência do empregado ao seu empregador, conforme preceitua o artigo $03^{\circ}$ da CLT (BRASIL, 1943).

Conforme Carlos Henrique Bezerra Leite o empregado não é "dependente" do empregador, e sim a sua atividade laboral (física, mental ou intelectual) é que fica em um estado de sujeição ao poder (diretivo, regulamentar e disciplinar) do empregador" (LEITE, 2018).

A falta de qualquer dos requisitos supracitados acarreta óbice intransponível a caracterização do vínculo jurídico de empregado, afastando a relação jurídica da tutela da legislação trabalhista. Portanto, a inexistência de subordinação, o que ocorre na prestação de serviços dos autônomos, descaracterizaria a relação de emprego.

Impende ressaltar que a reforma trabalhista (Lei 13.467/17) introduziu o artigo 442-B da CLT, fazendo menção expressa que o trabalho autônomo não caracteriza a relação de emprego:

"Art. 442-B - A contratação do autônomo, cumpridas por este todas as formalidades legais, com ou sem exclusividade, de forma contínua ou não, afasta a qualidade de empregado prevista no art. $3^{\circ}$ desta Consolidação". (BRASIL, 1943). 
O trabalho autônomo é regulado pelo Código Civil, nos artigos 593 a 609, sendo aquele prestador de serviço que assume os riscos do negócio e não subsiste na relação quaisquer um dos requisitos legais que caracterizam o vínculo empregatício.

\subsection{Relação de emprego e o trabalho sob demanda por meio de aplicativo}

No caso, o ponto crucial para definir se os prestadores de serviços por meio de demanda se enquadram como empregados ou autônomos, está no campo da subordinação.

Alguns dos requisitos legalmente previstos, para a configuração de uma relação de emprego, são verificados na prestação de serviços por meio de aplicativos. A pessoalidade, mesmo que pairando a controvérsia sobre poder se substituir por outro prestador de serviços, pode ser verificada vez que o cadastro nas plataformas é de pessoas físicas, com inserção de fotos, dados pessoais, informações do veículo utilizado, deixando claro que a prestação de serviços deve ser pessoal. Inclusive, por meio da avaliação dos consumidores, verifica-se que a prestação dos serviços é de forma pessoal. A não eventualidade também resta demonstrada mesmo que não haja exigência de um horário de trabalho pelas plataformas. A prestação contínua do trabalho junto à plataforma, o que é facilmente monitorado pelo próprio aplicativo, já configura uma prestação de serviço não eventual. Quanto a onerosidade, não resta dúvidas uma vez a plataforma é utilizada com o objetivo de se receber uma remuneração.

Contudo, a grande controvérsia está na subordinação. Ao mesmo tempo que os prestadores não possuem autonomia para ditar as regras da prestação de serviços que são impostas pelas plataformas, como exemplo temos os valores dos serviços ofertados, de outro lado temos a liberdade dos prestadores de serviços que podem escolher dia, hora, modo de realizar seu trabalho, sem qualquer ingerência, controle ou punição pela plataforma.

Ocorre que, sem a presença de um dos requisitos legais, o vínculo empregatício não pode ser reconhecido, fato pelo qual é ainda tão controversa essa questão. Devido a isso, as demandas judiciais começaram a surgir, tendo o Judiciário se posicionado de maneira ainda contraditória, conforme será visto a seguir.

\section{4- O posicionamento do Judiciário frente ao trabalho sob demanda por meio de aplicativos}


Com a popularização da prestação de serviços por meio de plataformas digitais os Tribunais no país começaram a se debruçar sobre as implicações jurídicas deste tipo novo de prestação de serviços, principalmente por não haver ainda regulamentação ainda definida dessa atividade.

A primeira decisão sobre o tema, versa sobre a empresa Uber, tendo sido proferida pelo Dr. Márcio Toledo Gonçalves, Juiz do Trabalho da $33^{\mathrm{a}}$ Vara do Trabalho de Belo Horizonte/MG, nos autos de $\mathrm{n}^{\circ}$ 0011359-34.2016.5.03.0112. Nela, o vínculo de emprego foi reconhecido o autor. (BRASIL, 2017a.). Contudo, neste mesmo processo, a decisão ao ser analisada em sede de recurso ordinário, foi integralmente reformada pela $09^{\text {a }}$ Turma do Tribunal Regional do Trabalhando, tendo o i. Relatora, Des. Maria Stela Álvares da Silva Campos, deixado claro não haver presença dos requisitos legais como subordinação e pessoalidade.

Com entendimentos controversos quanto a questão, foram proferias várias decisões nos Tribunais Regionais do Trabalho do País, algumas caracterizando o vínculo de emprego e outras deixando claro ser a prestação de serviços autônoma, sem qualquer subordinação jurídica.

O Superior Tribunal de Justiça também já se posicionou sobre o assunto. Em 04/09/2019, foi publicada a decisão da Segunda Seção do Superior Tribunal de Justiça, no Conflito de Competência n. 164544 (BRASIL, 2019a.), sob relatoria do Ministro Moura Ribeiro, que, por unanimidade, reconheceu ser a competência do juízo cível e não trabalhista, para o julgamento da indenização pleiteada por um motorista de aplicativo que teve sua conta suspensa, decidindo ainda que não se tratava de uma relação de trabalho. Apesar de transitada em julgado a decisão não implica que esteja pacificada no âmbito da justiça. (NUNES, 2020).

O Tribunal Superior do Trabalho também já analisou a questão e o posicionamento da $04^{\mathrm{a}}$ e $05^{\mathrm{a}}$ Turmas foi pelo não reconhecimento do vínculo de emprego ao argumento de que a autonomia na prestação de serviços é claro, vez que o motorista pode escolher o momento em que ficaria conectado à plataforma, tratando-se mais de um serviço de mediação, o que não caracterizaria o vínculo de emprego. Ressalta-se que o posicionamento das duas turmas não diz respeito ao posicionamento do Tribunal Superior do Trabalho como um todo, vez que ainda não houve decisão vinculante sobre o tema. 
Portanto, diante das divergências jurisprudenciais, principalmente no cenário contemporâneo brasileiro, e a fim de se evitar a insegurança jurídica que pode prejudicar inclusive o funcionamento das empresas de prestação de serviços por plataforma no Brasil, que se faz necessária a regulamentação sobre o tema.

Cabe salientar, através de uma análise econômica do Direito, que a insegurança jurídica que atormenta a questão suscitada leva à muitas empresas deixarem de investir no mercado brasileiro. Deixar a cargo do entendimento judiciário traduzir as demandas concretas, com elevados poderes econômicos, é trazer a baila um risco elevado à situação econômica do país, que encontra um quadro cada vez mais elevado de desempregados.

Conforme Fabiano Teodoro de Rezende Lara:

"A Análise Econômica do Direito tem como pressuposto a idéia de que o Direito é instrumento para conseguir os fins sociais, sendo que fim a conseguir é o da eficiência econômica. (...) função do Direito desloca-se de estabelecimento de parâmetro de equilíbrio entre forças da demanda e da eficiência econômica". (LARA, 2009)

Por isso, é necessária a regulamentação governamental, principalmente por intermédio de lei, para que se possa garantir a segurança na prestação dos serviços, o que implica inclusive no preço do produto ofertado que não mais levará em consideração os riscos de condenações judiciais que atualmente são computados.

Por isso, importante analisar o projeto de Lei n.3.748/20, que traz um novo cenário de regulamentação da prestação dos serviços por meio de aplicativos, não caracterizando como vínculo de emprego, seguindo a maior tendência dos entendimentos judiciais, mas garantindo aos prestadores de serviços benefícios, inclusive previdenciários, uma proteção jurídica mínima, o que poderia tirar estes trabalhadores deste limbo jurídico.

\section{5- O projeto de Lei n. 3.748/2020}

Na Câmara dos Deputados e no Senado Federal, há inúmeros projetos de leis em tramitação que visam tratar de direitos dos trabalhadores sob demanda por meio de aplicativos e os projetos se divergem entre considerar como empregados, na qual serão assegurados os direitos celetistas, ou como autônomos com garantias mínimas para sobrevivência e manutenção da dignidade do trabalhador. 
A título de exemplo, cita-se o projeto de lei n. 5.069/2019 de autoria do deputado Gervásio Maia e do projeto de lei n. 3.577/2020 de autoria do deputado Márcio Jerry que determinam que deverá ter o vínculo empregatício nestas relações. O projeto de lei n. 5.622/2019, apensado ao PL 5.069/2019, altera a Lei n. 13.640, de 2018, para reconhecer a relação de emprego entre o motorista de aplicativo e as empresas que operam o aplicativo.

Por sua vez, o projeto de lei n.3.944 foi feito exclusivamente durante a pandemia e determina o uso de Equipamentos de Proteção Individuais -EPI;s. O projeto de lei n. 3.599/20 beneficia exclusivamente os trabalhadores que executam as atividades por meio de bicicletas. E ainda, o projeto de lei n. 3.570/2020 dispõe sobre o aumento do valor das entregas, salário mínimo e seguro acidente.

A maioria dos projetos de leis apresentados em 2020 foram apensados ao PL 6015 de 2019 de autoria do Deputado Mário Heringer (PDT/MG) que reconhece como empregados os trabalhadores por meio de plataforma digitais, que apensou os projetos de lei 3.515/2020; $3.538 / 2020 ; 3.554 / 2020 ; 3.572 / 2020 ; 3.577 / 2020 ; 3.748 / 2020 ; 3.797 / 2020$.

Dentre tantos, um dos mais expressivos e polêmico é o projeto de Lei n. 3.748/2020, que em 09.12.2020 também foi determinado o apensamento ao PL n. 6.015/2019.

\section{1- O não enquadramento no conceito de empregado dos trabalhadores pelo PL n. 3.748/2020 e os direitos assegurados}

De autoria da Deputada Tábata Amaral, tendo posteriormente solicitado a coautoria os seguintes deputados: João H. Campos - PSB/PE, Professor Israel Batista - PV/DF, Flávia Arruda - PL/DF, Tereza Nelma - PSDB/AL, Bacelar - PODE/BA, Reginaldo Lopes - PT/MG, Luisa Canziani - PTB/PR, Raul Henry - MDB/PE em seu artigo primeiro já descarta a aplicação da CLT - Consolidação das Leis do Trabalho (CLT) ou seja, os prestadores de serviços no caso, não serão considerados empregados e assim não terão os mesmos direitos garantidos as trabalhadores regidos pela norma celetista, vejamos:

\footnotetext{
"Institui e dispõe sobre o regime de trabalho sob demanda. O CONGRESSO NACIONAL decreta:

Art. $1^{\circ}$ É instituído o regime de trabalho sob demanda, nas condições estabelecidas na presente Lei.

Parágrafo único. Aos trabalhadores em regime de trabalho sob demanda não se aplicam as disposições da Consolidação das Leis do Trabalho (CLT), aprovada pelo Decreto-Lei $\mathrm{n}^{\circ}$ 5.452, de $1^{\circ}$ de maio de 1943 ”.
} 
Por sua vez, o $\S 4^{\circ}$ do artigo $2^{\circ}$ prevê que o regime de trabalho sob demanda não impede a caracterização de vínculo de emprego entre o trabalhador e um determinado cliente, se presentes os requisitos legais previstos na CLT.

Portanto, em que pese descartar o vínculo jurídico de emprego inicialmente, caso comprovado que na relação evidenciou os requisitos legais para configuração do vínculo, com determinado cliente, o trabalhador poderá buscar judicialmente seus direitos a fim de garantir o recebimento dos benefícios típicos da relação empregatícia.

Tem-se ainda que apesar do projeto de lei descartar totalmente o vínculo jurídico de emprego, e considerar a prestação de serviço como autônoma, garante benefícios tipos de uma relação empregatícia e ainda protege o trabalhador.

O intuito do legislador é garantir o mínimo de direitos para a categoria de trabalhadores, mantendo a relação transparente e segura quando determina que deve demonstrar que os valores pagos atendem ao mínimo legal e demais regras do PL 3.748, e, ainda, fornecer extrato discriminado sempre que solicitado seja pelo trabalhador ou órgãos de fiscalização.

Assim, o trabalhador sob demanda, terá direito a perceber o Seguro-Desemprego quando descadastrado por iniciativa da plataforma, cujo valor do benefício corresponda a 1 (um) salário-mínimo e será concedido por um período máximo de 3 (três) meses, de forma contínua ou alternada, a cada período aquisitivo de 16 (dezesseis) meses, contados da data do descadastramento que originou habilitação anterior.

Nos termos do artigo 16 o trabalhador sob demanda é filiado ao Regime Geral de Previdência Social - RGPS na qualidade de segurado empregado, ficando a cargo da plataforma a inscrição do trabalhador sob demanda na Previdência Social, conforme dispuser o Regulamento.

Há também previsão de proteção da saúde dos trabalhadores o que se verifica no artigo 10, na qual deverá fornecer equipamentos de proteção individual ou arcar com os custos quando adquiridos pelo trabalhador o instruindo quanto ao uso e ainda prevenir: I - o trabalho em condições de fadiga; II - repercussões negativas na saúde e segurança dos trabalhadores; III - o descumprimento de normas pelos trabalhadores; e IV - consequências sociais ou ambientais negativas, que deverão ser fiscalizados pelos órgãos de fiscalização, sindicatos e entidades associativas de trabalhadores. 
Pelo PL n.3.748 a plataforma deverá impor medidas que evitem o assédio, violência e discriminação entre trabalhadores e clientes bem como adotar as medidas de acessibilidade para permitir que os serviços por ela oferecidos possam ser executados por trabalhadores com deficiência.

Destaca-se que a justiça do trabalho será a competente para dirimir os conflitos do contrato (artigo 25). Ao garantir que a justiça especializada em relações empregatícias aprecie as demandas sobre o tema, é sem dúvida prestigiar o trabalhador, já que os contratos de prestadores de serviços autônomos são discutidos na justiça comum, notoriamente conhecida como mais morosa.

Portanto, o Projeto de Lei prevê amparo legal em diversos aspectos que beneficiam os trabalhadores, como se empregados fossem sob o regime celetista.

\section{2- Análise crítica do PL n. 3.748: Criação de uma terceira modalidade de trabalho ou tentativa de flexibilizar as relações trabalhistas?}

Mesmo diante da precariedade dos serviços que gera insegurança, dúvida, riscos, desconfiança e ausência de continuidade, o aumento do índice de desemprego no país, com a expansão dos contratos temporários e movimentos de flexibilização das relações fomentadas pelo próprio governo federal aumenta ainda mais o número de trabalhadores sob demanda.

Tem-se que atualmente o trabalhador em apreço não está sujeito ao controle de jornada, não sofre penalidade se não prestar serviço e determina o modo e o tempo de trabalho e ainda é responsável pelos riscos da atividade, como no caso do Uber que precisam possuir ou alugar o carro arcando com os custos relativos à operação do veículo.

Por sua vez, não se pode considerar como autônomo o trabalhador que está subordinado a toda uma estrutura com prestação de serviços impostas pelas plataformas digitais.

Não é objeto da presente definir se o prestador de serviços sob demanda por meio de aplicativos enquadra-se como empregado ou autônomo. Todavia, imperioso destacar que a realidade fática demonstra que apesar da liberdade para estabelecer os seus próprios horários de trabalho, tal fato não pode ser suficiente para afastar a caracterização da subordinação. Ressalta-se que cada contrato deverá ser analisado de forma minuciosa, como vem fazendo o judiciário apurando as questões fáticas para configuração dos requisitos legais que configuram o vínculo jurídico de emprego. 
No caso, o projeto de lei apesar de definir o serviço prestado como autônomo, ao mesmo tempo garante direitos próprios de empregados, o que permite concluir que houve a criação de uma terceira modalidade de prestador de serviço, como vem ocorrendo no Direito comparado.

A terceira modalidade, ainda não conceituada no Direito do Trabalho, surge à medida em que há definição de características e regras que transitam entre as duas modalidades. Como dito, apesar de o PL afastar o regime celetista, impõe benefícios que somente os empregados possuem.

Mesmo afastando o vínculo empregatício das relações de trabalho sob demanda, o PL 3.748 não afasta os princípios basilares que norteiam o Direito do Trabalho, tais como o princípio da proteção, que se expressa nas regras in dubio pro operário; da norma mais favorável e da condição mais benéfica; princípio da irrenunciabilidade; princípio da primazia da realidade; princípio da razoabilidade e princípio da boa-fé.

Ainda que desconsidere que houve a criação implícita de outra terceira modalidade de contrato de trabalho, mas de flexibilização das relações empregatícias, a mesma ocorreu considerando as peculiaridades que o contrato impõe. Não é demais lembrar que a autonomia de horários, escolha de clientes e dias de trabalho como ocorre com a maioria dos aplicativos em estudo, bem como determinadas características da subordinação estrutural beneficia o trabalhador em detrimento do regime jurídico de emprego.

O que se percebe é que contrato de trabalho para prestação dos serviços sob demanda por meio de aplicativos, hoje em constante crescimento e prestado por milhares de trabalhadores sem qualquer tipo de regulamentação, ofende aos princípios fundamentais da dignidade da pessoa humana (art. $1^{\circ}$, III) e dos valores sociais do trabalho (art. $1^{\circ}$, IV), os objetivos fundamentais de construção de uma sociedade livre, justa e solidária (art. $\left.3^{\circ}, \mathrm{I}\right)$ e de erradicação da pobreza e da marginalização.

Não bastasse, aumenta as desigualdades sociais porque há o empobrecimento da classe em detrimento das plataformas digitais e seus criadores, violando, portanto, o artigo $3^{\circ}$, III da Constituição Federal que determina a redução das desigualdades sociais, o direito fundamental à isonomia (art. $5^{\circ}$, caput).

Ao garantir o mínimo de direitos aos trabalhadores, haverá a diminuição da desigualdade social entre o prestador de serviço até então de forma precária e os proprietários das plataformas digitais e/ou contratantes. 
Assim, o referido projeto de lei atende aos anseios da sociedade, não viola princípios basilares do Direito do Trabalho que protegem ao trabalhador, vez que se estendeu aos trabalhadores sob demanda diversos direitos que hoje são dos trabalhadores cujos contratos de trabalho são regidos pela CLT.

\section{6- CONCLUSÃO}

A Declaração Universal de Direitos Humanos em seu artigo XXIII, insere o direito ao trabalho como direito humano. A dignidade da pessoa humana está atrelada a um trabalho digno em condições justas e favoráveis de trabalho e à proteção contra o desemprego.

Diante do desemprego e do avanço tecnológico, uma opção encontrada como meio de sobrevivência por diversos trabalhadores é a prestação de serviços por demanda por meio de aplicativos.

A atual situação na qual encontra-se os prestadores de serviços por meio de aplicativos é precária e atinge a sua dignidade, sobretudo porque está se consolidando o entendimento judicial de que não há vínculo jurídico de emprego nos Tribunais Superiores.

Ainda que não se classifique o serviço prestado por meio de aplicativos como relação de emprego, mas como autônomo, as condições mínimas de proteção ao desemprego e de valorização do trabalho devem ser garantidas aos trabalhadores desta categoria.

O projeto de Lei n.3.748/2020 apesar de descaracterizar o vínculo jurídico de emprego garante benefícios aos trabalhadores do setor, que hoje não possuem.

Portanto, o projeto de Lei n. 3.748/2020, cria uma nova modalidade de trabalhador para o Direito do Trabalho, de conceito específico ainda não definido, mas que veio garantir o equilíbrio social há muito almejado nesta relação, atendendo aos anseios da sociedade, sobretudo à classe dos trabalhadores, que ficarão protegidos em caso de acidentes, desemprego, licença maternidade, indenização justa dos custos, etc. Atenderá também às plataformas e aos próprios consumidores que, diante da insegurança jurídica que se tem hoje sobre o tema, acabam embutindo nos preços os altos custos dispendidos com os processos judiciais. 


\section{REFERÊNCIAS}

APPS COMO UBER E IFOOD SÃO FONTE DE RENDA DE QUASE 4 MILHÕES DE AUTÔNOMOS.www.infomoney.com.br,2019.Disponível em:

https://www.infomoney.com.br/carreira/apps-como-uber-e-ifood-sao-fonte-de-renda-dequase-4-milhoes-de-autonomos/. Acesso em: 13 jan.2021.

BRASIL. Consolidação das Leis Trabalhistas. Decreto-Lei n. 5.452, de $1^{\circ}$ de maio de 1943. Disponível em: http://www.planalto.gov.br/ccivil_03/decreto-lei/del5452.htm. Acesso em: 18 jan. 2020.

BRASIL. Projeto de Lei n. 3.748/2020. Disponível em:

https://www.camara.leg.br/proposicoesWeb/fichadetramitacao?idProposicao $=2257468$.

Acesso em: 17 jan. 2021.

BRASIL. Projeto de Lei n. 5.069/2019, 5.622/2019, 5.069/2019, n. 3.515/2020, n.3.538/2020; n.3.554/2020; n.3570/2020, n.3.572/2020; n.3.577/2020; n. 3.599/20, n.3.748/2020; n.3.797/2020, n.3.944/2020. Disponível em:

http://www4.planalto.gov.br/legislacao/portal-legis/legislacao-1/projetos-de-leim/apresentacao\#acontent. Acesso em: 16 abr. 2021.

BRASIL. Tribunal Regional do Trabalho da $3^{\text {a }}$ Região. Processo $n^{\circ} 0011359$ -

34.2016.5.03.0112. Uber do Brasil Tecnologia Ltda. x Rodrigo Leonardo Silva Ferreira. Juiz do Trabalho Márcio Toledo Gonçalves. Disponível em: https://pje-

consulta.trt3.jus.br/consultaprocessual/detalhe-processo/00113593420165030112. Acesso em: 15 jan. 2021.

BRASIL. Tribunal Regional do Trabalho da $2^{\mathbf{a}}$ Região. Processo $\mathrm{n}^{\circ} 1000123-$

89.2017.5.02.0038. Uber do Brasil Tecnologia Ltda. x Marcio Vieira Jacob. Juíza do Trabalho Ana Carla Santana Tavares. Disponível em: https://pje.trt2.jus.br/consultaprocessual/detalheprocesso/10001238920175020038. Acesso em: 15 jan. 2021.

BRASIL. Tribunal Regional do Trabalho da $\mathbf{1}^{\mathbf{a}}$ Região. Processo $\mathrm{n}^{\circ} 0100797$ 28.2017.5.01.0036. Uber do Brasil Tecnologia Ltda. x Phelipe Saldanha da Costa e Cirne. Juiz do Trabalho Fabio Correia Luiz Soares. Disponível em: https://pje.trt1.jus.br/consultaprocessual/detalhe-processo/01007972820175010036. Acesso em: 15 jan. 2021.

BRASIL. Tribunal Regional do Trabalho da 13 $^{\text {a }}$ Região. Processo $n^{\circ} 0000699-$ 64.2019.5.13.0025. Uber do Brasil Tecnologia Ltda. x Richard Harrison de Lima Fernandes. Juiz do Trabalho Aercio Pereira de Lima Filho. Disponível em: https://pje.trt13.jus.br/consultaprocessual/detalhe-processo/00006996420195130025. Acesso em: 15 jan. 2021. 
BRASIL. Superior Tribunal de Justiça. Conflito de competência n ${ }^{\circ} 164.544$ - MG. Relator Ministro Moura Ribeiro. 28 de agosto de 2019. Disponível em: https://ww2.stj.jus.br/processo/revista/documento/mediado/?componente=ITA\&sequencial=1 857953\&num_registro=201900799520\&data=20190904\&formato=PDF Acesso em: 11 jan. 2021.

CRELIER, Cristiane. Número de pessoas que trabalham em veículos cresce 29,2\%, maior alta da série. www.agenciadenoticias.ibge.gov.br, 2019. Disponível em:

https://agenciadenoticias.ibge.gov.br/agencia-noticias/2012-agencia-denoticias/noticias/26424-numero-de-pessoas-que-trabalham-em-veiculos-cresce-29-maior-altada-serie. Acesso em: 13 jan. 2021.

FATOS E DADOS SOBRE A UBER. wwww.uber.com.br, 2021. Página inicial. Disponível em: https://www.uber.com/pt-BR/newsroom/fatos-e-dados-sobre-uber/. Acesso em: 13 jan. 2021.

KALIL, Renan Bernardi. A regulação do trabalho via plataformas digitais. Renan Bernardi Kalil - São Paulo: Blucher, 2020.

LANGLEY, Paul; LEYSHON, Andrew. Platform capitalism: The intermediation and capital isation of digital economic circulation. Finance and Society, v. 3, n. 1, 2016, p. 4-7.

LARA, Fabiano Teodoro de Rezende. A Análise Econômica do Direito como método e disciplina. E-civitas Revista Científica do Departamento de Ciências Jurídicas, Políticas e Gerenciais do UNI-BH. Belo Horizonte, vol. I, no 1, nov-2008. ISSN: 1984-2716.

LEITE, Carlos Henrique Bezerra. Curso de Direito do Trabalho. São Paulo: Saraiva Educação, 2018.

NUNES, Djalma Otávio Moreaux; MENDES, Marcelo de Sá; SANTANA, Rodrigo. Mercado de aplicativos: implicações no mercado de trabalho em virtude de reconhecimento de vínculo empregatício no brasil. Boletim Economia Empírica. Vol I. Número III. 2020.

RIBEIRO, Gabriel Francisco. Greve não para apps, mas mostra força de entregadores; nova data é votada. www.uol.com.br, 2020. Disponível em:

https://www.uol.com.br/tilt/noticias/redacao/2020/07/01/greve-nao-para-apps-mas-afetasistema-e-mostra-forca-de-entregadores.htm. Acesso em: 13 jan.2021.

SÜSSEKIND, Arnaldo. Da relação de trabalho. Revista do TRT/EMATRA - $1^{a}$ Região, Rio de Janeiro, v. 20, n. 46, jan./dez. 2009. 